\title{
Universiteit
}

Leiden

The Netherlands

\section{Legitimacy and the virtualization of dispute resolution} Mommers, L.

\section{Citation}

Mommers, L. (2005). Legitimacy and the virtualization of dispute resolution. Artificial Intelligence And Law, 13, 207-232. Retrieved from https://hdl.handle.net/1887/13064

Version:

Not Applicable (or Unknown)

License:

Leiden University Non-exclusive license

Downloaded from: $\quad$ https://hdl.handle.net/1887/13064

Note: To cite this publication please use the final published version (if applicable). 


\title{
Legitimacy and the virtualization of dispute resolution
}

\author{
LAURENS MOMMERS \\ eLaw@Leiden, centre for law in the information society, P.O. Box 95202300 RA, Leiden, \\ Netherlands \\ (E-mail: l.mommers@law.leidenuniv.nl)
}

\begin{abstract}
For any type of institutionalized dispute resolution, legitimacy is a crucial characteristic, as legitimate dispute resolution promotes, for instance, general trust in state institutions and participation in economic activity. A lack of legitimacy will prevent the acceptance of dispute resolution, and thereby its use. Although many textbook definitions limit the meaning of legitimacy to legality, in its every-day use legitimacy is in fact a much broader concept. It encompasses different criteria relating to the nature of dispute resolution: is a form of dispute resolution properly embedded in a reliable institutional environment?, and: are its outcomes properly underpinned? Virtualization concerns the ways in which information and communication technologies affect administration, communication, accessibility and assessment. As an example of virtualization in dispute resolution, a scenario about on-line feedback is scrutinized. This scenario comprises the implementation of a feedback system to enable participants in an instance of dispute resolution to comment on various aspects of the dispute resolving process.
\end{abstract}

\section{Introduction}

One of the most obvious new sources of conflicts is the internet. Nowadays, millions of people do business with other people they do not know in any other way than by the articles they offer and - sometimes - the opinions about them provided by other customers. Conflicts can, for instance, arise from different interpretations of information, from errors or damage during transport, or from fraud. As a consequence of such conflicts (except for, probably, the ones arising from fraud), and the disadvantages of administration of justice, there is a growing interest in alternative types of dispute resolution. They can provide a solution if using public administration of justice is disproportionate, takes too much time, is too costly, or endangers the relation between the parties. With the advent of information and communication technology (ICT), especially the opportunities offered by the internet, on-line types of dispute resolution have emerged. Some of these types are based on existing, off-line types of dispute resolution, such as 
on-line mediation. Some types could be claimed to have emerged as completely new types of dispute resolution, for instance the dispute resolution options offered to eBay-clients (eBay, website).

\subsection{TYPEWRITERS AND DISPUTES}

At first sight, ICT does not seem to cause changes that are fundamentally different from changes invoked by, for instance, reorganizing administrative tasks. This is not so strange, because in many cases, ICT is a replacement of or addition to existing processes, tasks or technologies: electronic timesheets instead of a time clock, a word processor instead of a typewriter, an electronic database instead of a card-index, and an electronic form instead of a paper questionnaire. But in fact, many of these changes have much more impact over a longer period of time, because they do not only change the ways in which 'things are done' (performing tasks, communication), they also change 'things' themselves (new tasks, new forms of communication).

The word processing metaphor can be used for this. Today, the basics of a typewriter are still present in a word processor. But not only have lay-out capabilities increased tremendously, also, the way in which texts are written has changed completely: re-using and re-arranging paragraphs and sentences has become easy, references to electronic sources can be included, spelling and style can be checked, and electronic resources can be consulted. Although none of these changes can be qualified as 'fundamental', we can see in practice that texts sometimes bear the signs of electronic origination ('copy and paste' letters), and workflow has changed (many people now type their own letters instead of leaving the work to a secretary).

Dispute resolution is quite a different ballgame from word processing, of course. However, a process similar to word processing may be going on, in that the current landscape of dispute resolution can change considerably under the influence of ICT. Not only because of the direct way in which ICT influences the handling of certain tasks, but also because ICT provides new origins for conflicts, and new ways of handling conflicts. The goal of this article is to make an inventory of the possible consequences of those changes for the legitimacy of dispute resolution. But, just as ICT and dispute resolution change over time, legitimacy criteria may evolve. The use of 'legitimacy' as an evaluative concept requires its operationalization. The evolution of the legitimacy concept implies that any operationalization is only of temporary value.

\subsection{OPERATIONALIZING LEGITIMACY OF DISPUTE RESOLUTION}

Operationalizing a concept means forcing its original, vague meaning into something that can be qualified, or even quantified ( $c f$. Jost and Major 2001 
for different approaches to operationalizing legitimacy). The latter is very similar to giving grades to students: operationalizing desired knowledge and skills into learning goals, then into exam questions, and finally into a grade for the students' answers to the exam questions. A grade is a useful instrument, but it tells about as much about the presence of certain knowledge and skills in a student, as a smile on the face of a person tells us about his well-being. In this article, legitimacy is operationalized only to a limited extent: criteria are provided that may be translated into concrete questions. These criteria provide $a$ framework, not the framework. It should be taken at face value: determining the meaning of concepts is not an exact science.

What criteria can be used for operationalizing legitimacy? The meaning of legitimacy is explained in different ways by various authors, and it differs with respect to both its area of application (in this article, only the legitimacy of dispute resolution is relevant) and with respect to its institutional, procedural or substantive grounding. In institutional approaches, legitimacy is derived from properly founded institutions (courts of law, arbitration courts, mediators) and the powers attributed to them ( $c f .$, e.g., the consent criterion in Shapiro's 1981 approach). In procedural approaches, legitimacy is found in the proper adherence to established procedures, such as an adversarial process ( $c f$. ., e.g. Luhmann 1969). In substantive approaches, the content is evaluated of the 'product' whose legitimacy should be determined ( $c f .$, e.g., Shapiro's 1981 approach, insofar as consent is based on the content of a court's decision).

Tamanaha (2001) casts doubt on the very value of the legitimacy enterprise, which he describes as the project to provide a legal system with some kind of justification. Tamanaha's critical comments with respect the socalled 'evolutionary myth' and 'mirror thesis' regard the implausibility of the assumption that the norms and values of a society are reflected in positive law. Although his criticism seems appropriate with respect to specialized areas of law (such as administrative law) and so-called 'legal transplantations' (positive law of a certain society is directly implemented in a completely different society), legitimacy can be derived from the norms and values of society - especially in those cases where dispute resolution is very basic, such as with the new, simple forms of dispute resolution triggered by web trading. Tamanaha's objections to the legitimacy enterprise thus do not take away the need for assessment tools with respect to the legitimacy of dispute resolution.

\subsection{STRUCTURE OF THIS ARTICLE}

Changes in ICT cause changes in dispute resolution. In this article, an evaluation framework is introduced to assess the legitimacy of dispute 
resolution under these changing circumstances. The framework is based on a synthesis of different legitimacy criteria. They are accommodated in two sets: those classified as reliability criteria, and those classified as substantive criteria. It is argued that the legitimacy concept has a context-dependent meaning, which can be construed as consisting of various reliability and substantive criteria, relevant to the research area at hand. These criteria can be used for a normative evaluation: how does virtualization change dispute resolution, and what does this transformation mean for the legitimacy of dispute resolution?

In Section 2, a scenario for the transformation of dispute resolution is discussed. This scenario comprises the opportunity for the parties in an instance of dispute resolution to give their opinion on the procedure followed and the solution provided. In Section 3, the concept of virtualization will be explained, and four virtualization themes will be scrutinized with respect to the feedback scenario for dispute resolution. In Section 4, the legitimacy concept is analyzed in terms of reliability and substantive criteria. In Section 5 , these legitimacy criteria are applied to potential uses of ICT in dispute resolution in general, and to the feedback scenario in specific, thereby enabling a statement about the consequences of such a scenario for the legitimacy of dispute resolution. In Section 6, a conclusion is provided.

\section{Dispute resolution: a scenario for on-line feedback}

Virtualization scenarios show how dispute resolution can be altered through the use of information and communication technology. Although many specific virtualization scenarios can be sketched with respect to dispute resolution, this article will mainly focus on one scenario. This scenario concerns the use of institutionalized on-line feedback in the context of dispute resolution. It is based on the success of eBay's feedback system, which may set an example for an open assessment of the quality of dispute resolution. After a brief discussion of the merits of eBay's feedback system, I will discuss the preconditions that apply to the use of a similar system for dispute resolution.

\subsection{HOW THE WEST WAS WON: FEEDBACK INSTITUTIONALIZED}

eBay is probably the most successful example of using interaction to promote e-commerce. Feedback profiles in eBay function as an effective means for buyers to anticipate the trustworthiness of the seller - and vice versa ( $c f$. Feedback Forum, website). Positive feedback profiles are worth money: sellers with a large positive feedback profile can earn more by selling a particular item than people with a small or negative feedback profile. Such a 
positive feedback profile decreases the risk premium that buyers wish to collect for on-line buying through a seller not known to them. Feedback on eBay is relatively one-dimensional, as it mainly concerns regular buyers' and sellers' problems (late or non-arrival, damaged items, late or non-payment, wrong item description). The system is not completely fool-proof either: negative feedback has such an impact, that sellers may be forced to give into unreasonable buyers' demands to prevent the buyer from giving negative feedback, and vice versa. And the system is prone to manipulation, as little can be done against a carefully constructed positive (possibly fake) feedback profile which is used to start bigger, fraudulent transactions in a later stage.

Nevertheless, the feedback system on eBay works quite well (considering the growth of eBay despite of trust issues between buyers and sellers), and it may set an example for designing feedback systems in other areas. In on-line dispute resolution, feedback may be used during or after a specific instance of dispute resolution. In the first case, it can be part of the exchange of arguments and commenting on them. Such use is related to argumentation systems (cf., e.g., Gordon 1995; Verheij 1996, 2003; Lodder 1998). In the second case, it is used by a party in an instance of on-line dispute resolution to comment on the role of the dispute resolver, the dispute resolving institution, or the other party in a dispute. This article focuses on the latter type of feedback. Potential clients of dispute resolvers can use such feedback to make an informed choice among different types of dispute resolution, and learn more about dispute resolver's specializations, methods and capacities.

\subsection{FEEDBACK IN DISPUTE RESOLUTION}

What concrete form could a feedback system get in a dispute resolution environment? A number of issues has to be addressed to be able to make a statement about a concrete form for such feedback: first, whether the feedback will be made public; second, whether the feedback will be processed; third, the types of subjects to be covered; fourth, additional information to support feedback; and fifth, the type of dispute resolution and conflict suitable for the use of a feedback system. After the discussion of these five issues, a concrete format for a feedback system will be discussed.

The first issue is: will the feedback (or information based on feedback) be made public at some point in time? Feedback ought, in principle, only be made public after the current instance of dispute resolution has been closed, either succesfully or unsuccesfully, so that the dispute resolution process itself is not interfered with. Making feedback public potentially means disclosing classified information. Therefore, monitoring, editing and anonymizing the feedback is a prequisite for preventing the occurrence of insulting language, off-topic comments and violation of confidentiality agreements. However, to 
remain an independent party, the dispute resolving institution probably ought not itself perform the monitoring task.

The second issue is: will the feedback be processed into a more general form? Using feedback most effectively means generalizing the outcomes into statements regarding different topics or quality criteria. Just as the monitoring task, generalizing outcomes should be done by an independent party, because generalizations tend to have a normative character. Being the subject of evaluation, the dispute resolving institution would not be objective in performing this task. Generalization of outcomes is important, as reading and assessing individual opinions by potential clients of a certain form of dispute resolution would probably take too much of their time.

The third issue is: what types of subjects will be covered? Subjects to be covered by a feedback system are, for instance, (1) impartiality and integrity, (2) expertise, (3) treatment, (4) unity of law, and (5) pace and timing. These subjects were actually operationalized in a project for quality measurement in Dutch administration of justice (Project Kwaliteit 2002). Some of these criteria are also mentioned as legitimacy criteria ( $c f$. Section 4). The operationalization of quality criteria could therefore prove very useful for the operationalization of legitimacy criteria in the context of a feedback system for dispute resolution.

The fourth issue is: what additional information can be offered to support giving feedback? Parties giving feedback should be well informed regarding the type of dispute resolution that they are involved in. The quality of their feedback increases if they know what they can expect of the dispute resolver and the dispute resolving institution. Otherwise, their feedback might be off-topic, incorrect or even insulting. For instance, the parties in a mediation should know that they cannot expect a judgement by the mediator. Thus, the most obvious type of support in giving feedback to an instance of dispute resolution is to provide information on its procedural characteristics.

The fifth issue is: what type of dispute resolution and what type of conflict are the most suitable ones for using a feedback system? Traditional types of dispute resolution, such as administration of justice, are probably less suitable for implementing feedback systems. On the one hand, the stakes are higher (administration of justice is completely institutionalized, and thereby susceptible to damage to its reputation), and on the other hand, proper institutionalization probably means that persons already put more trust in them. Relatively new types of dispute resolution, such as mediation, and especially on-line types of dispute resolution, such as the negotiation and mediation services offered by SquareTrade, demand background information in order to be seen as a proper alternative to traditional types of dispute resolution. Such feedback is currently not available on the SquareTrade website (SquareTrade, website). 
A concrete form for a feedback system thus depends on choices with regard to making public and generalizing feedback, evaluating certain characteristics, and offering additional information. For instance, if a feedback system should be added to the mediation services of SquareTrade, making feedback public will definitely provide a benefit to potential new users, as they will learn about past experiences, and thereby be able to decide whether the service suits them. A generalization of feedback will give them surveyable information on the nature of the experiences of past users.

Subjects to be commented on through such a system include, for instance, the impartiality of the mediator, the way in which the mediators approaches the two parties, the pace with which the procedure is completed, and the quality of the arguments the mediator uses. Questions about these aspects can be posted to the parties after the successful or unsuccessful completion of a mediation. In case of an unsuccessful mediation, questions should be asked about the reasons for finishing the mediation without a solution. With this information, it may become possible to attribute the lack of success to a party, to the mediator or to different circumstances. A reminder of the basic characteristics of on-line mediation may focus the parties' feedback to those comments that do justice to this particular type of dispute resolution.

As SquareTrade is an on-line service, the most obvious form for a matching feedback system is an on-line system, preferably maintained by an independent organization set up to supervise alternative dispute resolution. To obtain a realistic image of the opinions of all clients, there should be some kind of incentive to provide feedback. By keeping the number of questions limited, response can be optimized. As SquareTrade is mainly active in the eBay community, using an overall system design similar to that of eBay is probably the most effective.

\section{Virtualization of dispute resolution scrutinized}

Virtualization of dispute resolution comprises the processes that occur mainly as a result of the use of information and communication technology. These processes constitute the decreasing dependence on specific locations in time and space for acts and processes related to dispute resolution, such as collecting and presenting information and interaction between agents. More concretely, virtualization in dispute resolution refers to distance hearings of witnesses, synchronous (e.g., video telephony) or asynchronous (e.g., e-mail) communication between parties and the dispute resolver, and the use of on-line information resources and knowledge-based systems.

Reiling (2003) classifies different forms of virtualization by the function of civil administration of justice. The four functions she distinguishes are mere title provision, notarial functions, settlement and judgement. For each of 
these functions, she provides examples of ICT support. In the area of mere title provision, there are on-line systems for title provision to money claims. These facilitate the administrative acts attached to such procedures. For the notarial function, facilitation of administrative acts can be combined with the making available (and sometimes the automated application) of a calculation model, for instance in divorce cases. Settlement cases may profit from the availability of (court-annex) mediation through e-mail. Finally, in case of the judgement function, for instance, facilitation of information access, digital case files and distance testimony are possible forms of ICT support.

Virtualization allows for, e.g., more flexibility in arranging meetings of parties, and in accessing and exchanging information. From these examples, and Reiling's discussion of ICT support in dispute resolution, four functional areas can be derived in which changes occur: administrative processes, forms of communication, accessibility of information and services, and assessment of information and services. For each of these areas, it will be assessed how a feedback system for dispute resolution fits in with the changes described.

\subsection{FOUR FUNCTIONAL AREAS OF VIRTUALIZATION}

To indicate the way in which technological developments may affect dispute resolution, I discuss the changes that occur within the four functional mentioned in the previous section.

Administrative processes have traditionally been substantially affected by the introduction of information and communications technology. This is also valid for ICT within institutions that deal with dispute resolution. Within this functional area, we find technology for, e.g., the registration of information about specific cases and the parties involved. Registration, archiving and planning can benefit from new technologies, although in reality, many of the potential benefits are barred by lack of standardization and organizational problems. The lack of proper interfaces between different systems often causes unnecessary work, for instance multiple input of identical data. Still, electronic delivery of case data, electronic case files, and management information systems potentially cause changes in the efficiency of dispute resolution. Reiling (2003) names consistency, speed and access as benefits of using ICT in the judiciary.

Under the heading of forms of communication, several developments can be distinguished. New forms of communication are developed, such as e-mail, chat, and internet forums, changing the way in which people interact. For instance, interaction can have various forms between synchronous and asynchronous communication, meaning that persons may exchange their ideas immediately, or think a short while about them. The traditional division between telephone and mail has turned into a continuum, featuring chat 
applications, voice-mail, internet forums and e-mail. With the introduction of these new communications means, people are much less dependent on specific locations and points in time to be able to interact. These advantages can be used in dispute resolution, especially if the parties do not live near each other.

Accessibility of information and services has experienced a profound change due to the introduction of information and communication technologies. The transition from paper to screen has resulted in a vast amount of possibilities to rearrange bits and pieces of information in order to facilitate access, for instance through the use of hypertext. Accessibility of information also benefits from being able to search the whole text instead of only a selected number of keywords, and being able to search very fast through large numbers of documents. The way documents are presented can be adjusted dynamically, and physical possession of an information source is no longer needed, because of network accessibility, unrestricted by opening hours of physical institutions. The same goes for services, which can be accessed from a distance, and used through longer hours. Dispute resolution can profit from these changes by providing parties with better information on procedures.

Assessment of information and services can change considerably as a result of the introduction of information and communication technology. The diminishing of personal contact may lead to a different assessment of, for instance, interpersonal communication. The assessment may become more focused on its content ( $c f$. Mommers 2003). The lack of face to face communication may increase the distance between information providers and information users, resulting in a potentially more neutral assessment of the merits of a piece of information. As an opposite effect, this distance may also lead to indifference, apathy, or to swiftly escalating arguments (which often occur in, for instance, on-line forums and mailing lists, and even in normal e-mail correspondence). Assessment may also change because it becomes easier to compose multidisciplinary teams, assessing different aspects of a certain problem or dispute.

\subsection{TYPIFICATION OF A FEEDBACK SYSTEM}

The feedback scenario sketched in Subsection 2.2 can be typified in terms of the four functional areas of change discussed above. Obviously, such a system primarily facilitates the assessment of information and services. But it also affects the functional areas of forms of communication and accessibility of information and services. Administrative processes may be the subject of feedback given by parties, but in the scenario sketched above, they are not.

With respect to forms of communication, a feedback system adds an additional channel for communication to the existing ones in dispute 
resolution. Not only does this add opportunities (improving quality of dispute resolution), it also involves risks (escalating arguments). For instance, giving feedback after an instance of dispute resolution is almost without obligations to the other party if (a) the conflict has already been resolved and (b) there is no lasting relation between the parties. In such a case, a system for feedback may induce non-relevant or even vindictive comments. eBay's feedback system solves this problem by allowing meta-feedback (comments to feedback) and reciprocal feedback (persons A and B may give each other feedback). The reason why this system works (at least, it does not trigger many vindictive comments) is, as noted before, the economic value of a positive feedback profile. Feedback profiles, containing the accumulated feedback given to a person or institution in its role in dispute resolution, can play a role similar to eBay feedback profiles if the community is substantial enough to maintain such profiles.

With respect to the accessibility of information and services, the accessibility of dispute resolution is facilitated by the presence of feedback systems. Such systems may be especially relevant with respect to potential users of a specific type of dispute resolution, and to potential clients of a certain dispute resolving institution. Using the information made available through feedback systems gives those persons a better starting point for assessing the advantages and disadvantages of types and institutions of dispute resolution. The low barriers of obtaining such information may lead them to better-informed choices, such as is already the case with users of eBay, who can use a feedback profile to decide whether they are willing to place a bid. The same could be the case with on-line dispute resolution services such as the ones offered by SquareTrade, enabling an informed choice for a specific type and institution of dispute resolution.

With respect to assessment of information and services, assessment opportunities for dispute resolution benefit greatly from the introduction of a feedback system. Information and communication technologies provide an easy way to collect, edit, structure and articulate feedback. Parties in a finished instance of dispute resolution may be asked to provide feedback on a number of topics that concern their perception of, e.g., independence and impartiality, and the expertise of the dispute resolver, thereby actively contributing to the improvement of dispute resolution quality. If the instance of dispute resolution itself takes place in a virtual environment, feedback may also concern the specific characteristics of on-line communication. Additionally, comments may be provided on the behaviour of the other party in the dispute. The virtual (on-line) manifestation of a feedback system may make the assessment more reliable, as positive or negative biases are less likely to occur than in personal communication.

In the scenario discussed in Section 2.2, feedback is only given after the instance of dispute resolution. It cannot be ruled out, though, that parties can 
comment on each other's behaviour within the instance of dispute resolution. This will add a new point of view, comparable to that of eBay feedback profiles. If some form of dispute resolution is used within a particular domain, for instance e-commerce, participation in such feedback systems may be made mandatory. Their usefulness increases if these profiles can be re-used with other companies or organizations. Comments on a party in different instances of dispute resolution give valuable information to other persons or institutions who consider doing business with this party.

\section{Legitimacy}

Virtualization of dispute resolution can be assessed from a legal perspective. Various frameworks have been introduced that can be used for this purpose. Franken (2001) proposed the 'general principles of proper ICT use': availability, confidentiality, integrity, authenticity, flexibility, and transparency. This set of normative criteria is analogous to the general principles of good governance. In various Ph.D. theses, Franken's principles were used to assess the merits of certain legally relevant uses of ICT ( $c f$. Zwenne 1998; Groothuis 2004). A different evaluation framework, directly relevant to the subject at hand, is provided by article 6 of the European Convention of Human Rights, listing the characteristics that administration of justice should comply with, e.g., the demand of a fair and public hearing within a reasonable time by an independent and impartial tribunal established by law ( $c f$. the thorough analysis of case law on art. 6 by Schiavetta 2004).

However, in this article, a different perspective has been chosen: the legitimacy concept. In the current section, the legitimacy concept is analyzed. When using the term 'legitimacy', we have to ask ourselves what object it bears on. Apart from the content of the concept - which should tell us on the basis of which characteristics or criteria an object can be considered to be legitimate - we have to consider the type of object. It may be a procedure ('is civil action a legitimate procedure?'), an act ('is the behaviour of a judge legitimate?'), or a product, especially the results of a procedure ('is the decision of a judge legitimate?'). In defining legitimacy, we have to take the occurrence of these different objects into account.

Although legitimacy could be defined subjectively ('does a certain person consider this object to be legitimate?') or objectively ('is this object legitimate?'), I take legitimacy to be most viable as an intersubjectively defined term, because compliance with most of the criteria explained below can only be established on an intersubjective basis. On that basis, legitimacy can be defined - very abstractly - as 'agreement with intersubjective criteria establishing structural and substantive support for procedures, acts or products'. It is assumed that legitimacy is found in an open framework containing both 
reliability criteria that govern procedural and institutional characteristics of the legitimacy concept, and substantive criteria that govern material and content characteristics of the legitimacy concept. The reliability criteria are independence, impartiality, expertise, and accuracy. The substantive criteria are rationality, legality, reciprocity and consent. The value that is assigned to each of these criteria depends on the theory of legitimacy adopted (see Mommers 2002 for a similar approach to the concept of knowledge).

\subsection{RELIABILITY CRITERIA}

The reliability criteria primarily regard the environment in which disputes are resolved: what persons and institutions are involved, and how do they fulfil their tasks. Reliability thereby establishes a general tendency towards legitimate dispute resolution. The reliability criteria can be evaluated by setting standards and measuring the compliance of dispute resolving institutions and dispute resolvers with those standards. On the basis of general compliance, a prediction can be made for the legitimacy of specific dispute resolution outcomes. Also, the procedure followed in a specific instance of dispute resolution may be evaluated on the basis of the same criteria. Of the four criteria listed below, impartiality and expertise are mentioned in a quality project for administration of justice in The Netherlands (Project Kwaliteit 2002).

Independence - Independence puts the institutional environment of dispute resolution outside the immediate sphere of influence of other 'powers', such as the legislative and executive powers, press and action groups (Eshuis and Ter Voert 2003), and other dispute resolving institutions. Relevant connections between dispute resolving institutions and companies, government institutions etc. should be allowed only insofar as they do not exert influence on the way in which disputes are resolved. Independence also applies to individual dispute resolvers, who ought not to be influenced by external parties.

Impartiality - Impartiality implies that dispute resolvers only use objective factors in determining their stance in dispute resolution procedures. No relevant relations between the dispute resolver and the parties ought to exist prior to a procedure, and no such relations ought to be developed during the procedure. For instance, no 'secret' meetings between a dispute resolver and one of the parties are allowed, and there should be no preference of the dispute resolver towards one of the parties. Impartiality also applies to dispute resolving institutions, in the sense that these ought to encourage impartiality by establishing appropriate institutional policies.

Expertise - Expertise of dispute resolvers extends to three areas: knowledge of the area in which the dispute arose, legal knowledge and skills in that 
area, and knowledge and skills regarding dispute resolution. The kind of expertise needed depends heavily on the type of dispute resolution exercised. Each type of dispute resolution involves a particular combination of expertise needed: focus may be on one of the three expertise types. Whereas in administration of justice the focus will be on legal and procedural knowledge, focus in arbitration will be more on knowledge of the area in which the dispute arose, and focus in mediation will be on mediation skills.

Accuracy - Dispute resolvers' accuracy concerns the accurate character of their activities regarding procedures, judgements, and tasks they are responsible for, taking into account all facts and circumstances of a case, carefully examining their correctness. On an institutional level, precision should be guaranteed by the careful design, implementation and evaluation of relevant policies and procedures, supporting both the accuracy with which disputes are handled on the institutional level (their intake and distribution), and the accuracy of individual dispute resolvers' work.

\subsection{SUBSTANTIVE CRITERIA}

The substantive criteria primarily comprise the import of the actual steps in the procedures, and the content of the resulting solution. The substantive evaluation of the content of procedures and solutions requires the assessment of those individual procedural steps and solutions. However, a more general approach is also possible. Based on the outcomes of individual assessment of substantive criteria, more general conclusions can be drawn about, for instance, the rationality of a certain form of dispute resolution or a dispute resolving institution.

Rationality - The rationality of dispute resolution is constituted by the degree to which the dispute resolving procedure, its outcomes and the underlying grounds are well-constructed, i.e., the solutions follow from the grounds in accordance with the inference capacities of a reasonable person. Evaluating such inferences involves the relevance and proper use of arguments (for a discussion of justification, constituting an important part of rationality, $c f$. Nieuwenhuis 1976).

Legality - Often considered as a 'counterpart' of legitimacy, legality in fact seems to be one of the preconditions for legitimacy. Most dictionary definitions of the legitimacy concept actually denote legality. The legality criterion means that the dispute resolving procedures should be in conformance with the content of valid legal norms. Those legal norms can be derived from, e.g., valid legal rules and authoritative case law.

Reciprocity - Reciprocity concerns mutual relationships between people: giving and receiving goods and services establishes expectations regarding the balance between what to give to and what to expect from other people. In a 
more abstract sense, reciprocity means that people are able to form an idea of other people's needs and wishes, a form of empathy that can translate into acceptance of some types of dispute resolution, because these types propagate the mutual understanding of parties and acceptance of third-party judgements (cf. Pessers 1999).

Consent - Consent concerns the acceptance of individual judgements by the parties affected, and - in a wider sense - the acceptance of types of dispute resolution and legal systems by individuals or communities. Consent can both concern the attitudes of individuals and communities towards a certain type of dispute resolution, and their actual support in resolving disputes and executing solutions or judgements ( $c f$. Shapiro 1981).

\section{ICT and the legitimacy of dispute resolution}

The effective opportunities offered by ICT cause changes in the way people and organizations handle administrative matters, the way they communicate, the manner in which they access information and services, and the way in which they assess information and services. The effects of these changes can be both positive and negative. In this section, I will discuss the potential consequences of introducing information and communication technologies to the fulfilment of reliability and substantive legitimacy criteria. I will discuss those consequences for each of the functional areas of virtualization. For the feedback system sketched in Section 2.2, I will take a closer look at potential effects.

\subsection{AN ASSESSMENT OF VIRTUALIZATION}

What general effects can we expect from virtualization in dispute resolution to its legitimacy? In Section 3.1, I listed four functional areas of virtualization: administrative processes, forms of communication, accessibility of information and services, and assessment of information and services. These functional areas experience changes through the introduction of information and communication technology. In Tables I through IV, I list potential consequences of the introduction of ICT that facilitate each of the functional areas. These potential consequences are provided with respect to each of the legitimacy criteria.

In Table I, examples are given of opportunities and risks for the legitimacy of dispute resolution caused by the automation of administrative processes. The main influences can be found in two of the reliability criteria: independence and accuracy.

In Table II, examples are given of opportunities and risks for the legitimacy of dispute resolution caused by the increase in forms of communication. 
Influences can be found with respect to both reliability and substantive criteria.

In Table III, examples are given of opportunities and risks for the legitimacy of dispute resolution caused by increased accessibility of information and services. Influences can be found with respect to both reliability and substantive criteria, with a focus on the latter type.

In Table IV, examples are given of opportunities and risks for the legitimacy of dispute resolution caused by new possibilities to assess information and services. Influences can, again, be found with respect to both reliability and substantive criteria.

The overviews in Tables I through IV serve to provide an indication of the effects that virtualization can have on dispute resolution. They are a prelude to a more detailed discussion of the effects of using feedback in dispute resolution.

\subsection{AN ASSESSMENT OF FEEDBACK IN DISPUTE RESOLUTION}

In Section 5.1, an overview was given of positive and negative influences by ICT to the fulfilment of legitimacy criteria. The scenario for an on-line feedback system may further clarify those influences. The feedback system could be realized by making available on-line evaluation forms to anyone who has participated in an instance of dispute resolution. There is an incentive for everyone filling in those forms (for instance, viewing certain aspects of other persons' opinions is only possible after filling in one's own opinions). The forms contain questions operationalizing criteria such as independence and impartiality: 'Did the mediator say anything that would suggest a role he or she plays in a different organization?' and 'Did you feel the mediator gave equal attention to both parties' stances?'. The results of filling in such forms may provide valuable information about the perceived independence and impartiality of a dispute resolver, such as a mediator.

Depending on the actual use of the resulting information, the effects of processing such on-line feedback may vary. A potential positive consequence (an opportunity) measured by the independence criterion was provided in Table IV: the results of an on-line evaluation survey among mediation participants may make a mediation institute less vulnerable to external criticism. If the results of such a survey are positive, making available the results to the public may establish a higher esteem for the dispute resolving institution. For other institutions (such as competing dispute resolvers, sector organizations, ministries), it now becomes harder to exert influence on the mediation institute, thus increasing its independence. This is the case because of the 'credit' the mediation institute has gained. 


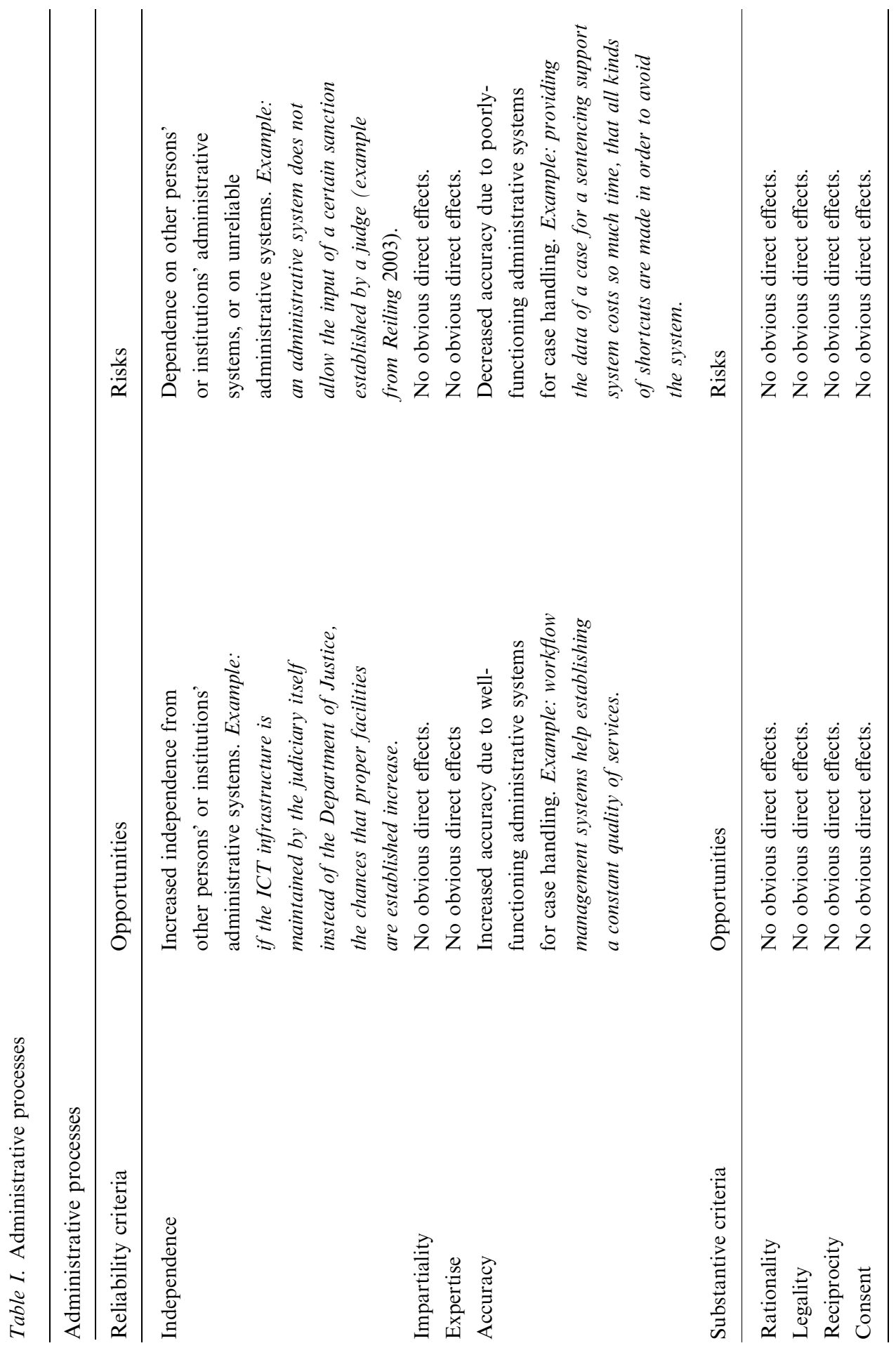




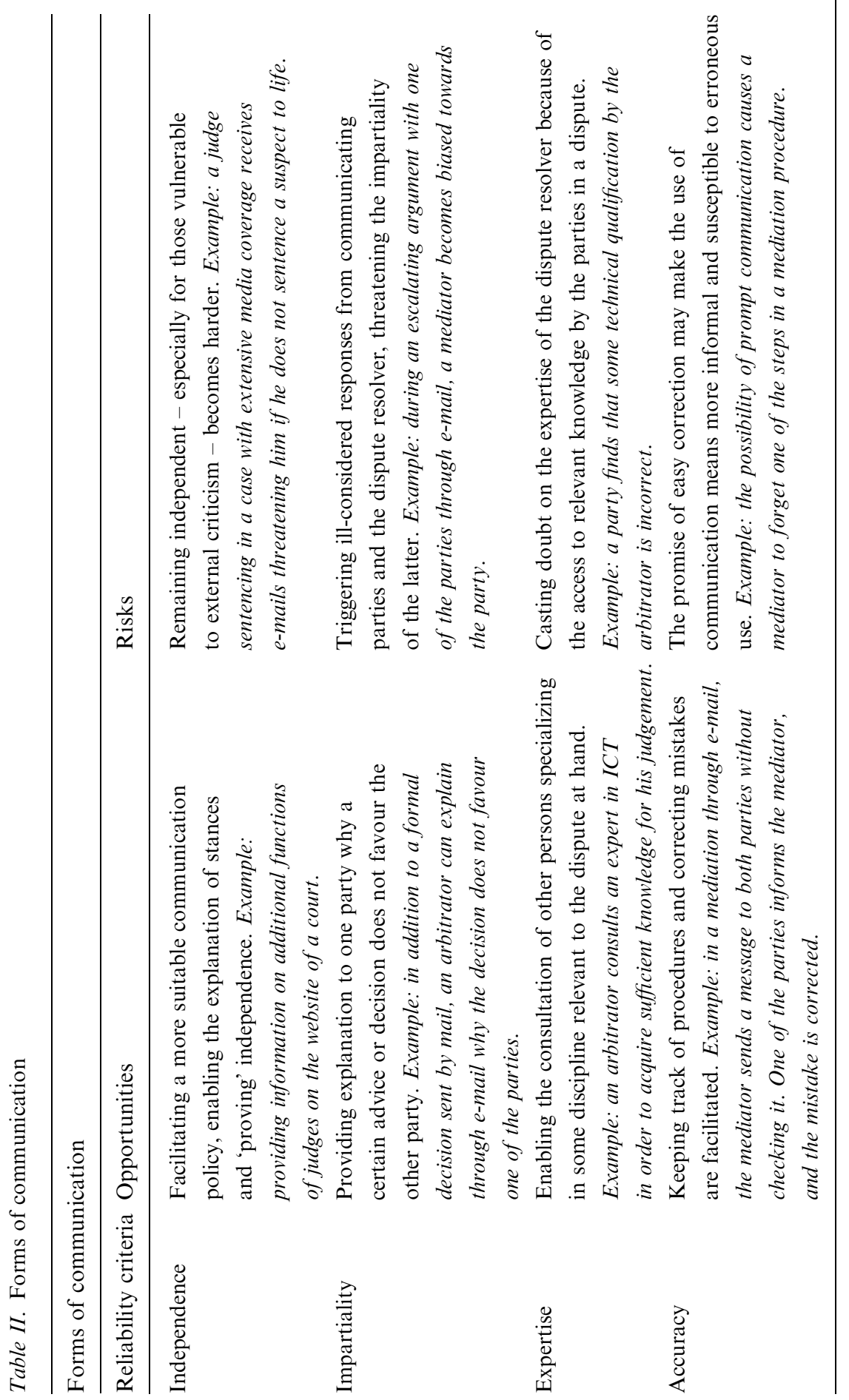




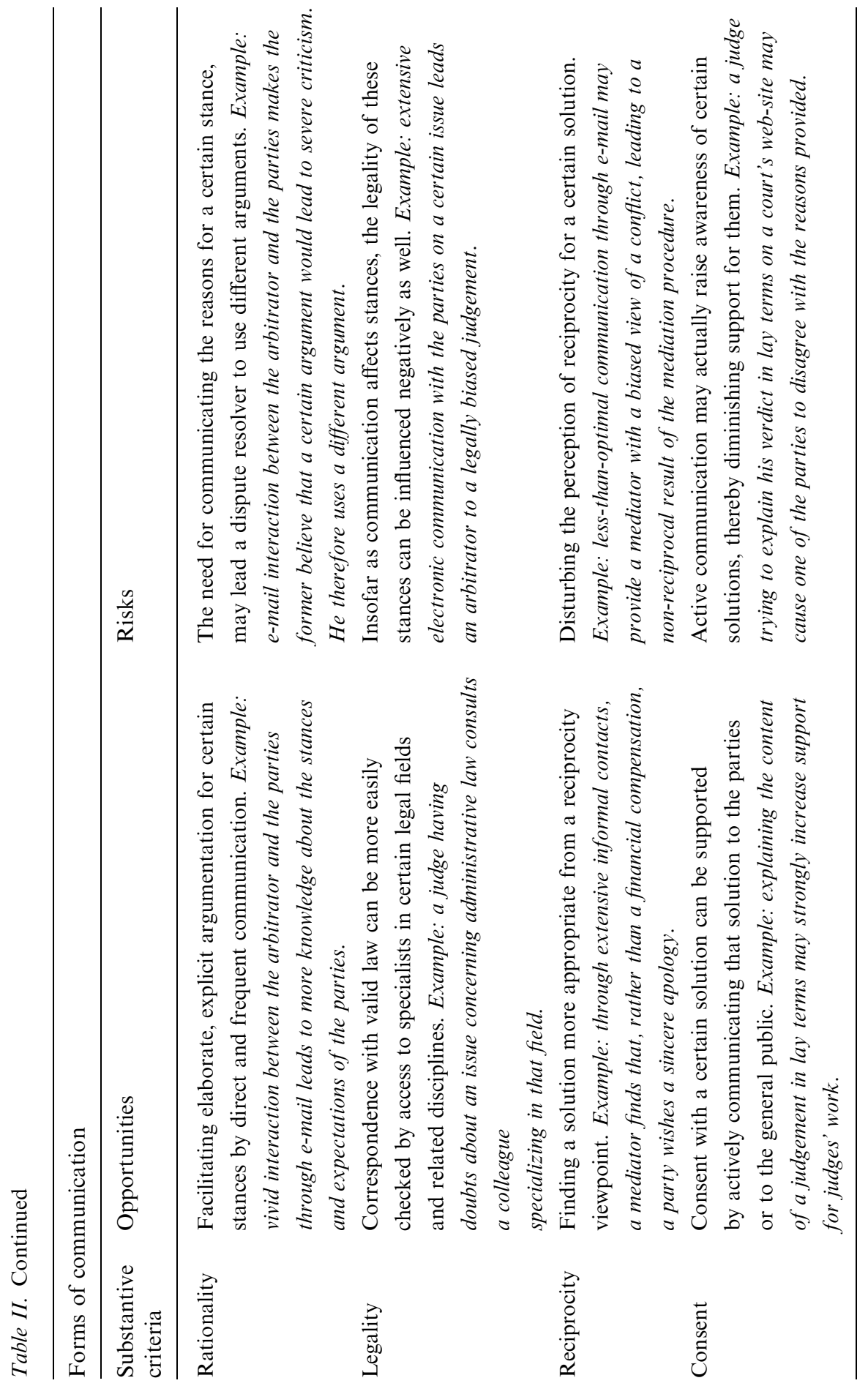




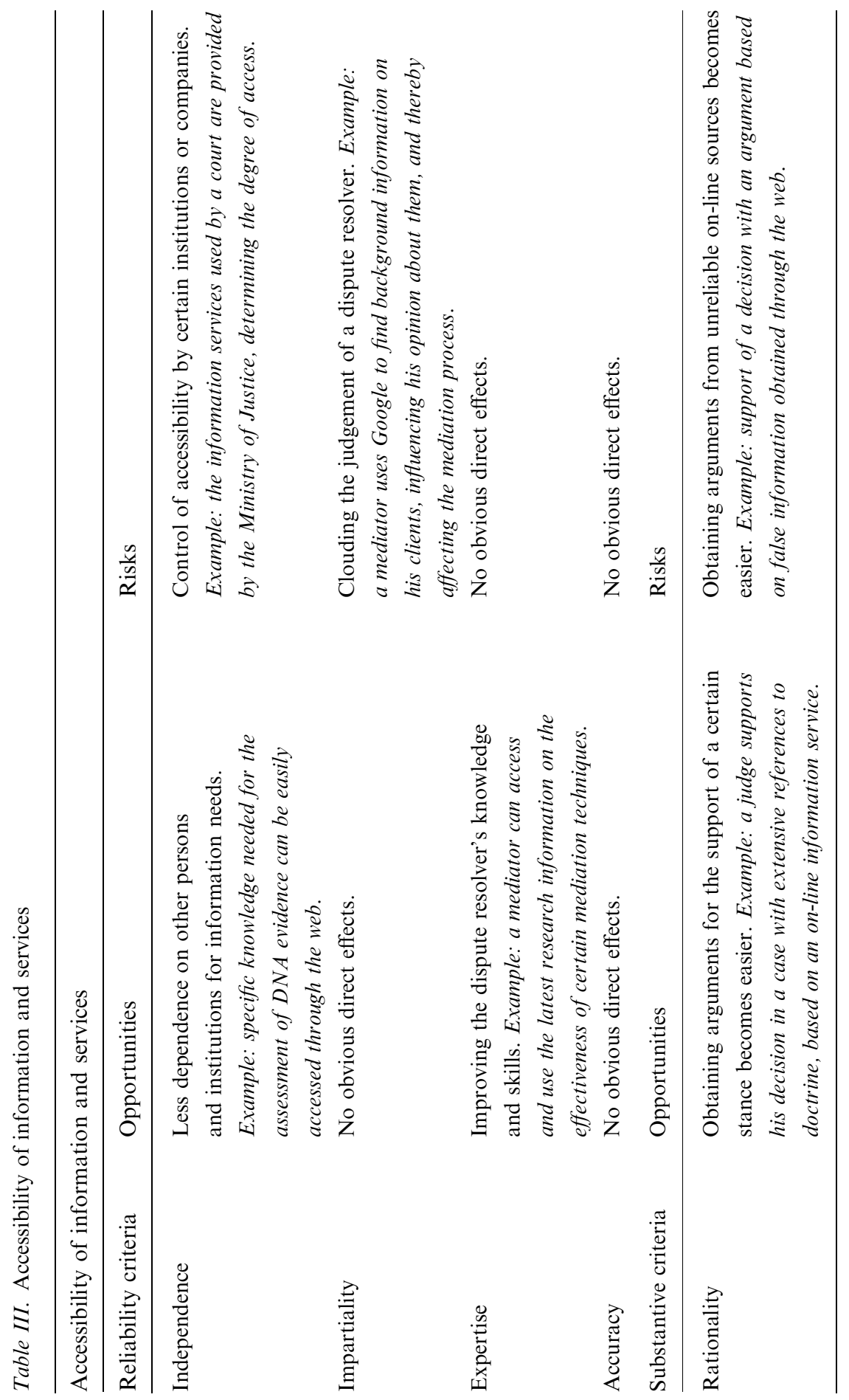




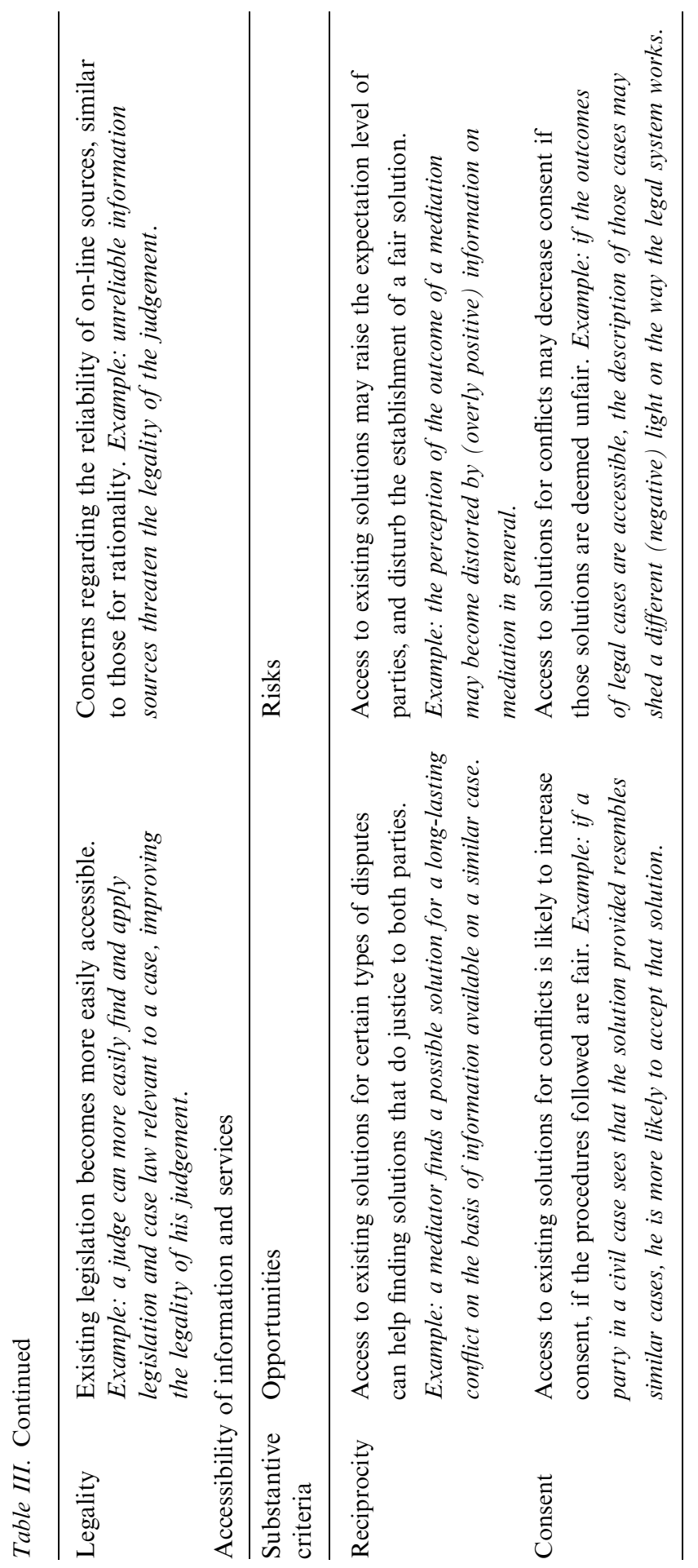


A potential negative consequence (a risk) measured by the independence criterion was also provided: the Ministry of Justice makes part of the funding of a court dependent on the quality of their work, measured by the on-line feedback of justiciables. This is, of course, only a risk insofar as the outcomes of the feedback system do not fairly reflect the quality of dispute resolution, and the measured quality is below average. By decreasing the funding, the quality of dispute resolution might be even further affected. Obviously, any type of assessment can be used for determining funding. If a court itself decides to introduce on-line feedback, it has some control over the issues to include in the feedback system. If a different institution - or the funding institution itself - decides to introduce such a system, the court lacks this kind of control.

Further remarks can be made with respect to the other examples of opportunities and risks with respect to reliability criteria listed in Table IV. With respect to impartiality, an example of an opportunity is: the presence of an on-line evaluation survey criticizing certain behaviour of a dispute resolver as impartial may lead to different, more appropriate behaviour. This is the case if the dispute resolver takes the feedback seriously, and adjusts his behaviour and solutions to behave impartially. An example of a risk is: on-line feedback may reduce impartial behaviour, without changing the actual solutions or decisions, thus causing 'hidden' prejudice. If impartial behaviour, caused by the introduction of a feedback system, is only 'window dressing', and solutions (especially decisions) are biased, this makes matters even worse than without a feedback system. With respect to expertise and accuracy, positive effects may occur: a participant in an arbitration may mention useful literature on a specific subject (improving expertise) and the critical remarks of participants in a mediation remind the mediator of his duty to maintain accuracy (improving accuracy).

With respect to substantive criteria, the following remarks apply. First, positive influence of a feedback system with respect to substantive criteria is to be expected along two routes: indirectly, through institutional processing of the feedback, and directly, through communication with the dispute resolver in a certain case. An assumption for the scenario in this article was that feedback is provided after an instance of dispute resolution. Thus, the second route does not apply to examples provided in this section. Second, for none of the substantive criteria in Table IV, risks are stated. However, there is a general risk involved in using a feedback system. A certain focus in the assessment (for instance: the degree to which a party agrees with the solution provided) may be reflected in the work of dispute resolvers. Thus, it may indirectly decrease the attention of dispute resolvers for issues such as argumentation, thereby diminishing the fulfilment of other substantive criteria. 


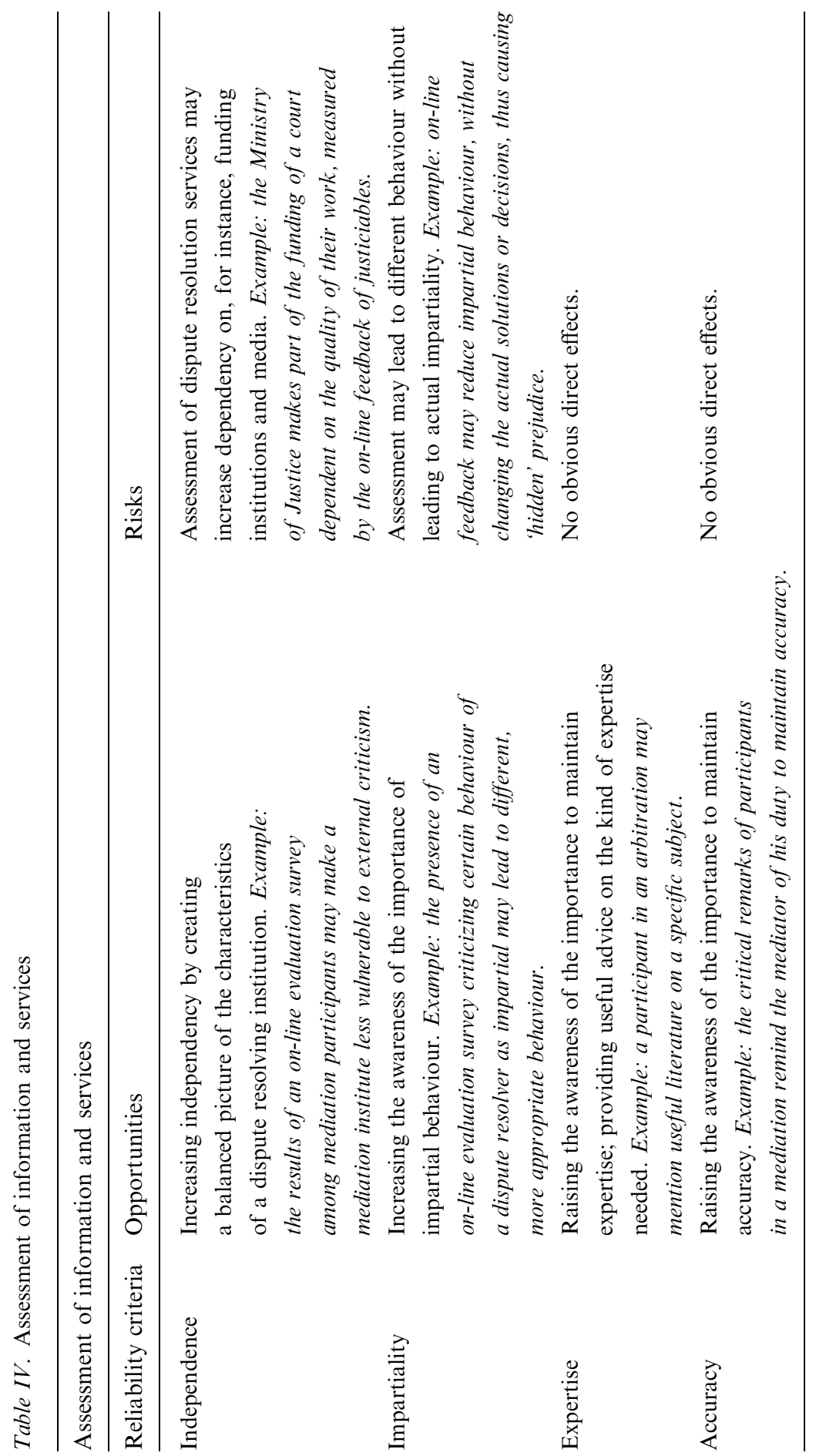




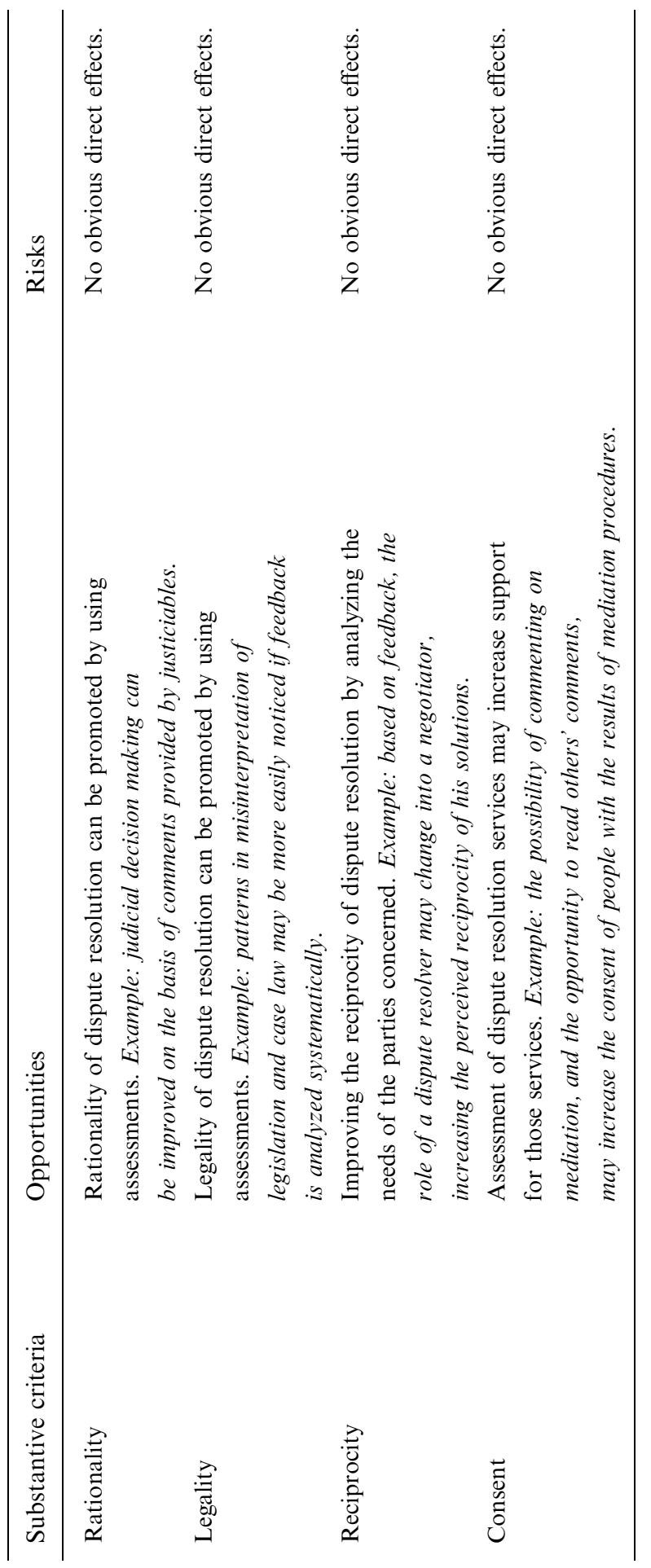


A potential positive consequence (an opportunity) by the rationality criterion was provided in Table IV: judicial decision making can be improved on the basis of comments provided by justiciables. Rationality can be positively influenced by detailed feedback on, for instance, specific reasoning steps, and by correcting apparent mistakes in the dispute resolver's work. The same goes for the other substantive criteria: the feedback by participants in dispute resolution can provide valuable information on the degree to which the solutions offered comply with the legality criterion. They can also provide an indication of the degree to which solutions favour both parties in a fair way (reciprocity), and the degree to which participants agree with the solution provided (consent). Of course, in order to provide such information, the on-line surveys should contain questions operationalizing these issues.

The reciprocity criterion poses an interesting challenge for feedback systems. Although reciprocity mainly concerns the relation between the parties in a dispute, it also affects the relation between parties and the dispute resolver. As an intermediate, or as an adjudicator, the dispute resolver channels and changes reciprocity relations between parties. Agreements, decisions and sanctions are also a way of restoring disrupted reciprocity relations. Improving the way in which dispute resolvers fulfil their task may be accomplished partly by providing feedback. The consent criterion may be influenced by the increased openness of dispute resolution. The possibility of giving feedback to an instance of dispute resolution may be a way of channeling dissatisfaction and thereby increasing consent for that form of dispute resolution. Of course, dispute resolving institutions' use of feedback to change or improve their work is an even more important part of increasing consent.

\section{Conclusions}

Information and communication technology causes changes in the way certain tasks are performed. The processes that occur as a consequence of this constitute virtualization. Virtualization consists of changes in four functional areas: administrative processes, forms of communication, accessibility of information and services, and assessment of information and services. Dispute resolution undergoes changes as a result of virtualization, not only because new technologies can support dispute resolution, but also because new types of conflicts arise. An example of technological support for dispute resolution is mediation through a chat application; an example of a new type of conflict is constituted by the disputes between buyers and sellers on eBay.

In this article, an example of ICT support for dispute resolution was explored, namely on-line feedback. Providing feedback is a way of 
assessing instances of dispute resolution, and it can be used to provide potential users with an impression of the specific merits and deficits of a certain type of dispute resolution, or with an impression of the quality of a specific dispute resolving institution. As such, it directly involves three functional areas. First, the way in which parties communicate may change as a consequence of the feedback that can be given after an instance of dispute resolution. Second, the accessibility of the service may be improved for the same reason. Third, the system enables the assessment of the characteristics of dispute resolution. Administrative processes may be affected indirectly, as a consequence of specific feedback on the way in which cases are handled.

Virtualization affects the legitimacy of dispute resolution. The reliability and substantive criteria explained in Section 4 provide a detailed framework in which the legitimacy of dispute resolution can be assessed. The assessment of institutionalized feedback in dispute resolution shows an ambiguous pattern of potential consequences. As became clear from the evaluation in Section 5, a clear prediction cannot be made about the net effect of feedback on the legitimacy of dispute resolution. However, it should still be possible to make claims about the suitability of feedback systems to help fulfil legitimacy criteria with respect to different types of dispute resolution, and about the preconditions that apply to the design of a feedback system.

Feedback is one of many possible ways to involve people actively in dispute resolution. It should be noted, however, that almost all technological developments can have both positive and negative consequences with regard to the fulfilment of legitimacy criteria. The introduction of new technology to support administration, communication, accessibility and assessment may thus raise questions about the legitimacy of the type of dispute resolution in which they are applied. Those questions can be answered more precisely for existing types of dispute resolution than for new types, because of the many uncertainties involved in the development of new (on-line) forms of dispute resolution. However, the legitimacy question is all the more important for 'virtual' dispute resolution, as its novelty will raise many related issues. The framework presented is meant to assess the suitability of ICT as a 'legitimacy promoter'.

\section{Acknowledgements}

The research described in this article is funded by the ITeR and ToKeN programmes of the Netherlands Organisation for Scientific Research under numbers 014-38-309 and 634.00.017. I would like to thank Aernout Schmidt and two anonymous referents for their comments on previous versions of this article. 


\section{Note}

1 Wherever the pronoun 'he' ('his') is used, it is used as an abbreviation of 'he or she' ('his or her').

\section{References}

Eshuis, R.J.J. and M. ter Voort (2003). De onafhankelijkheid en onpartijdigheid van rechters. Van insiders- naar outsidersperspectief. Justitiële Verkenningen, 29(1): 74-90.

Franken, H. (2001). Juridisch theoretische achtergronden. In Franken, H., Kaspersen, H.W.K and Wild, A.H.de (eds.), Recht en computer. Kluwer:Deventer.

Gordon, T.F. (1995). The Pleadings Game - An Artificial Intelligence Model of Procedural Justice. Kluwer Academic Publishers: Dordrecht.

Groothuis, M.M. (2004). Beschikken en digitaliseren: over normering van de elektronische overheid. Sdu Uitgevers: Den Haag.

Jost, J.T. and Major, B. (eds.) (2001). The Psychology of Legitimacy. Emerging perpectives on ideology, justice, and intergroup relations. Cambridge University Press: Cambridge.

Lodder, A.R. (1998). Dialaw - on legal justification and dialog games, Universiteit Maastricht: Ph.D. thesis.

Luhmann, N. (1969). Legitimation durch Verfahren. Hermann Luchterhand Verlag: Neuwied am Rhein und Berlin.

Mommers, L. (2002). Applied legal epistemology: building a knowledge-based ontology of the legal domain, Leiden: Ph.D. thesis.

Mommers, L. (2003). Application of a knowledge-based ontology of the legal domain in collaborative workspaces, Proceedings of the Ninth International Conference on Artificial Intelligence and Law, Edinburgh, UK, 2003, pp. 70-76.

Nieuwenhuis, J.H. (1976). Legimatie en heuristiek van het rechterlijk oordeel. Rechtsgeleerd Magazijn Themis 1976(6): 494-515.

Pessers, D.W.J.M. (1999). Liefde, solidariteit en recht. Een interdisciplinair onderzoek naar het wederkerigheidsbeginsel. Ph.D. thesis: Universiteit van Amsterdam.

Project Kwaliteit (2002). Project Kwaliteit. Kwaliteitssysteem voor het rechterlijk functioneren, Den Haag: Raad voor de Rechtspraak.

Reiling, D. (2003). Rechtspraak in de digitale delta. Nederlands Juristenblad 78(44): 22862291.

Schiavetta, S. (2004). The Relationship Between e-ADR and Article 6 of the European Convention of Human Rights pursuant to the Case Law of the European Court of Human Rights. JILT (Journal of Information, Law and Technology) 2004(1).

Shapiro, M. (1981). Courts. The University of Chicago Press: Chicago.

Tamanaha, B.Z. (2001). A General Jurisprudence of Law and Society. Oxford University Press. Verheij, H.B. (1996). Rules, Reasons, Arguments. Formal studies of argumentation and defeat. Ph.D. thesis: Universiteit Maastricht.

Verheij, H.B. (2003). Artificial argument assistants for defeasible argumentation. Artificial Intelligence 150(1-2): 291-324.

Zwenne, G.-J. (1998). Belastingheffing en informatieplichten. Sdu: Den Haag.

eBay: http://www.ebay.com.

Feedback Forum: http://pages.ebay.com/services/forum/feedback.html.

SquareTrade: http://www.squaretrade.com. 